\title{
SDS-PAGE Detection and Proteomic Characterization of Glycation- Sensitive Bovine Serum Albumin Peptides and Referenced in Comparison with Human Serum Albumin
}

\author{
Li-Jung Lai ${ }^{1,2}$, Fu-Long Huang ${ }^{1}$, Ping-Hui Cheng ${ }^{1}$ and Robin Y.-Y. Chiou ${ }^{{ }^{*}}$ \\ ${ }^{1}$ Department of Food Science, National Chiayi University, Chiayi, Taiwan, ROC \\ ${ }^{2}$ Department of Food Nutrition, Chung Hwa University of Medical Technology, Tainan, Taiwan, ROC
}

\begin{abstract} albumin (BSA) has been subjected to an in vitro glycation with fructose at $50^{\circ} \mathrm{C}$ for $24 \mathrm{~h}$ and SDS-PAGE analyzed. An original $50 \mathrm{KDa}$ peptide was disappearing with time along with appearance of the normally detected $97 \mathrm{KDa}$ glycated peptide. When bands of $50 \mathrm{KDa}$ and $97 \mathrm{KDa}$ were subjected to proteomic LC/ MS/MS analysis and MASCOT search with BSA gi|1351907 (NCBInr Database), the coverage ratios are $42 \%$ and $49 \%$, respectively. The segment of ECCDKPLLEK [aa 300-309 sharing common segment of KPLLEK with that in human serum albumin (HSA)] was only detected in the $50 \mathrm{KDa}$ peptide. In further search by manual queries addressed on $\mathrm{m} / \mathrm{z}$ values of the AGEs-precursor conjugates addressed on specified segments, K548 was of particular detected being active to form various AGEs-precursor conjugates. The adjacent 11 aa-segment of aa 545-555 (QIKKQTALVEL) is identical to that of HSA and deserves to use as a target to develop a measure in monitoring human blood glycation. Thus, segments of KPLLEK (aa 304-309) and QIKKQTALVEL (aa 545-555 containing K548 are of potency to use as a glycation-sensitive marker for development of rapid clinic assessment in surveillance of human health.
\end{abstract}

Publication History:

Extent of protein glycation, in particular serum albumins, glyco-conjugates formed between functional Received: August 12, 2017 proteins and the advanced glycation end-products (AGEs) has been regarded as an in vivo potential Accepted: October 14, 2017 marker related to metabolic syndrome and subsequent chronic diseases. In this study, bovine serum Published: October 16, 2017

\section{Keywords:}

Advanced glycation end products (AGEs), AGEs-precursor conjugates, Glycation-sensitive BSA peptides, MASCOT, Proteomic analysis

\section{Introduction}

Glycation is a general term covers a series of complex and spontaneous reactions among sugars and amino groups of proteins and further interactions with the advanced glycation end-products (AGEs). Extensive functional proteins involved in glycation result in feedback changes of their physical and functional properties and cause subsequent chronic diseases, such as cataract, arteriosclerosis and Alzheimer's disease [1-3]. Concerns no matter addressed on healthcare in monitoring the status of protein glycation for specified individuals or development of products bearing functions or effectiveness of anti-glycation, development of an accurate, handy and reliable clinic assessment as a potential disease marker is always a critical issue [1, 4-6]. Among the protein glycations, human serum albumin (HSA) glycation has attracted the most concerns and interests because HSA is the most abundant protein in the plasma and sensitive to undergo glycation. Albumin is one of the longest known proteins of plasma, bearing a wide spectrum of physiological functions. Thus, it has been commonly targeted and used for investigation of protein glycation. Among those, serum albumin is the general candidate of albumins. In human blood, albumin presents $50 \%$ of the normal individual's plasma protein [6]. BSA, with 583 amino acids and molecular weight of $66.28 \mathrm{KDa}$ [7], has $76 \%$ sequence homology and bears a similar ellipsoidal shape as HSA. Both have three homologous domains (I, II and III), which are connected together through helical extensions $[1,7,8]$.

Structural and physicochemical properties characterization of BSA and HSA have been intensively investigated [1, 8-10], a main difference for presence of two tryptophan residues (Trp-131 and Trp$214)$ in BSA, while one (Trp-214) is present in HSA [11,12]. The Tryp214 localized at domain II of HSA is suggested to have a role in its amyloid fibril formation [13]. Even very minor differences are present between BSA and HSA and perform more or less differently on their responsible functions, both share similar structure and exhibit most biochemical activities in general. In addition, available source, high grade of purity and affordable cost of BSA are appreciated by most users. Accordingly, BSA is regarded as a referenced standard protein and widely used in most laboratories. In this study, in addition to SDS-PAGE characterization of BSA peptides being sensitive to glycation, the peptides were subjected to LC/MS/MS analysis for proteomic figuration focused on some specific amino acid segments present in both BSA and HSA. Perspectives addressed on potential use of those unique segments as markers in product development for status surveillance of human health are raised for discussion.

\section{Materials \& Methods}

\section{Materials}

Bovine serum albumin [BSA, 98\% purity] and D-(-)fructose were purchased from Sigma-Aldrich Co. (St. Louis, MO). Potassium diphosphate and dipotassium hydrogen phosphate were purchased from Hayashi Pure Chemical Industries Ltd. (Osaka, Japan); 2-mercaptoethanol and sodium dodecyl sulfate [SDS] were purchased from Merck [Darmstadt, Germany]; Acryl/Bis solution, ammonium persulfate [APS], and TEMED were purchased from Amresco Inc. [Solon, $\mathrm{OH}$ ]; All other chemicals and solvents used in this study were of analytical grade.

"Corresponding Author: Dr. Robin Y.-Y. Chiou, Department of Food Science, National Chiayi University, 300 University Road, Chiayi, Taiwan, ROC; E-mail: rychiou@mail.ncyu.edu.tw

Citation: Lai LJ, Huang FL, Cheng PH, Chiou RYY (2017) SDS-PAGE Detection and Proteomic Characterization of Glycation-Sensitive Bovine Serum Albumin Peptides and Referenced in Comparison with Human Serum Albumin. Int J Clin Nutr Diet 3: 123. doi: https://doi.org/10.15344/2456-8171/2017/123

Copyright: @ 2017 Lai et al. This is an open-access article distributed under the terms of the Creative Commons Attribution License, which permits unrestricted use, distribution, and reproduction in any medium, provided the original author and source are credited. 
Citation: Lai LJ, Huang FL, Cheng PH, Chiou RYY (2017) SDS-PAGE Detection and Proteomic Characterization of Glycation-Sensitive Bovine Serum Albumin Peptides and Referenced in Comparison with Human Serum Albumin. Int J Clin Nutr Diet 3: 123. doi: https://doi.org/10.15344/2456-8171/2017/123

Page 2 of 5

\section{Glycation of BSA and fructose for various intervals}

In vitro glycation between BSA and fructose was conducted according to the procedure reported previously [14]. Briefly, BSA was dissolved in $0.2 \mathrm{M}$ phosphate buffered-saline ( $\mathrm{pH} 7.4$, containing $0.06 \%$ sodium azide) to yield a stock solution of $60 \mathrm{mg} / \mathrm{mL}$. This solution was applied to prepare a series of solutions containing fructose prepared in phosphate buffered-saline ( $\mathrm{pH}$ 7.4) and deionized water to a final concentration of $20 \mathrm{mg} \mathrm{BSA} / \mathrm{mL}$ and $0.5 \mathrm{M}$ fructose. Reaction mixtures were incubated at $50^{\circ} \mathrm{C}$ for $0,2,4,6,8,12$ and 24 h. After incubation, the reacted solutions were stored frozen at $-20^{\circ} \mathrm{C}$ for further analysis.

\section{Sample preparation for SDS-PAGE analysis}

From each tube after glycation reaction, $200 \mu \mathrm{L}$ reactant was withdrawn and transferred to a centrifugal concentractor (Vivaspin ${ }^{\circ} 2$ 10,000 MWCO PES tube, GE Healthcare, Amersham, UK) previously deposited with $1.3 \mathrm{~mL}$ deionized water. After mixing the tubes were centrifuged $(3000 \mathrm{~g})$ at $4^{\circ} \mathrm{C}$ for $5 \mathrm{~min}$. To each tube, deionized water was replenished to reach the level of $1.5 \mathrm{~mL}$ and pipetted for 50 times to thoroughly mix prior to centrifugation. This step was repeated once. Then, deionized water was replenished to reach the level of $1 \mathrm{~mL}$ and well mixed by repeated pipetting. From which $100 \mu \mathrm{L}$ of each solution was withdrawn and well mixed with $100 \mu \mathrm{L}$ of SDSPAGE sample buffer in an Eppendorf tube. The tubes were capped and heated in a water bath at $100^{\circ} \mathrm{C}$ for $10 \mathrm{~min}$. After heat treatment, $10 \mu \mathrm{L}$ of the solution was loaded into a well of a prepared SDSPAGE gel (10\% polyacrylamide separation gel containing $0.1 \%$ SDS) and subjected to electrophoresis (Mini-Protean 3 System, Bio-Rad, Hercules, CA) run at $100 \mathrm{~V}$ for $180 \mathrm{~min}$. Then, the gels were stained with Coomassie Brilliant blue R-250 (Sigma) for $20 \mathrm{~min}$ and destained with aqueous acetic acid/methanol solution $(100 \mathrm{~mL}$ of acetic acid and $200 \mathrm{~mL}$ of methanol per liter). The gels were scanned by an image scanner (U9909-H7L0, Amersham Biosciences, Uppsala, Sweden) and densitometric quantification using Fujifilm Multigauge ver. 3.0 Analysis Software (Fujifilm, Tokyo, Japan).

\section{Proteomic analysis}

From the SDS-PAGE, the band with estimated molecular weight (MW) $97 \mathrm{KDa}$ (Figure 1A) was cut from the $24 \mathrm{~h}$-glycation gel lane and the band with MW $50 \mathrm{KDa}$ was cut from the 0 h-glycation gel lane with a scalpel. The gel stripes were subjected to in-gel tryptic digestion, and then applied to Thermo Finnigan LCQ DECA XP Plus
Ion Trap Mass Spectrometer for peptides analysis (Instrument Center of National Cheng Kung University, Tainan, Taiwan). Peptides were separated by Zorbax 300 SB-C18 column $(150 \times 0.075 \mathrm{~mm}, 3.5 \mu \mathrm{m}$, Agilent ) using a mobile phase that contained Solvent A $(100 \% \mathrm{H} 2 \mathrm{O}$ with $0.01 \%$ Formic acid) and Solvent B (100\% Acetonitrile with $0.01 \%$ Formic acid ) at a flow rate of $0.2 \mu \mathrm{L} / \mathrm{min}$. The mobile phase composition was gradient from 0 to $10 \%$ solvent $\mathrm{B}$ for $2 \mathrm{~min}$ and then changed from 10 to $60 \%$ solvent $\mathrm{B}$ over $40 \mathrm{~min}$. The mass spectrometer was scanned from 500 to $3000 \mathrm{~m} / z$ range. The peptide fragments were searched by MASCOT web (http://www.matrixscience.com) interface from NCBInr 20121013 (21019903 sequences; 7205775305 residues) databases. The coverage ratios were calculated based on the sequences of BSA gi|1351907 and gi|3674602 (NCBInr Database). In further, 299 manual queries for targeted $\mathrm{m} / \mathrm{z}$ scanning addressed on the most likely glycol-conjugates formed between AGEs and the glycation precursor peptides in the $97 \mathrm{KDa}$ (Table 1) $[15,16]$.

\section{List of the proteomic search parameters}

Type of search : MS/MS Ion Search

Enzyme : Trypsin cuts C-term side of KR unless next residue is $\mathrm{P}$.

Variable modifications : Carbamidomethyl (C), Deamidated (NQ), Gln->pyro-Glu (N-term Q), Glu->pyro-Glu (N-term E), Oxidation (M).

Mass values : Monoisotopic

Protein Mass: Unrestricted

Peptide Mass Tolerance : $\pm 1 \mathrm{Da}$

Fragment Mass Tolerance: $\pm 1 \mathrm{Da}$

Max Missed Cleavages : 2

Instrument type: ESI-TRAP

Number of queries : 299.

\section{Results and Discussion}

\section{SDS-PAGE profiles of BSA after reaction with fructose}

SDS-PAGE spectra of BSA after reaction for glycation with fructose at $50^{\circ} \mathrm{C}$ for $24 \mathrm{~h}$ are shown in Figure $1 \mathrm{~A}$. Generally, in reference to the marker proteins $(\mathrm{M})$, in addtion to the major band of BSA located at MW $66 \mathrm{KDa}$ and crosslinking complex proteins visualized at the top of gel margin, bands with MW $97 \mathrm{KDa}$ and $50 \mathrm{KDa}$ were with detected. In comparison to original BSA spectrum (Lane 0), the bands with $97 \mathrm{KDa}$ are apparently the glycation products. Their band intensities increased with time of glycation (Figure 1B).

\begin{tabular}{|l|c|c|c|c|c|c|c|}
\hline Peptide Sequence & $\begin{array}{c}\text { aa } \\
\text { Start - end }\end{array}$ & $\mathrm{m} / \mathrm{z}$ & $\begin{array}{c}\text { Schiff } \\
\text { Base/AP } \\
(+162.02)\end{array}$ & $\begin{array}{c}\text { CML } \\
(+58.03)\end{array}$ & $\begin{array}{c}\text { Pyrraline } \\
(+108.02)\end{array}$ & $\begin{array}{c}\text { Imidazolon } \\
(+144.03)\end{array}$ & $\begin{array}{c}\text { AFGP } \\
(+270.07)\end{array}$ \\
\hline AEFVEVTK $^{*}$ & $249-256$ & 4621.8 & - & - & ++ & - & + \\
\hline ECCDKPLLEK & $300-309$ & 646.7 & - & - & - & - & - \\
\hline HLVDEPQNLIK $^{*}$ & $402-412$ & 653.6 & - & - & + & + & + \\
\hline QNCDQFEK $^{*}$ & $413-420$ & 534.9 & ++ & - & ++ & + & - \\
\hline LGEYGFQNALIVR & $421-433$ & 740.6 & - & - & - & - & - \\
\hline $\mathrm{K}^{\star} \mathrm{K}^{\star}$.QTALVELLK & $549-557$ & 507.9 & + & ++ & - & ++ & + \\
\hline $\mathrm{K}^{\star}$.TVMENFVAFVDK & $569-580$ & 708.5 & + & - & - & - & - \\
\hline
\end{tabular}

Table 1: Molecular weight sorting of the selected peptide+AGEs based on the dada set of the SDS-PAGE visualized 97 KDa band after subjection to LC-ESI/MS/MS proteomic analysis.

-: Absence +: presence 
Citation: Lai LJ, Huang FL, Cheng PH, Chiou RYY (2017) SDS-PAGE Detection and Proteomic Characterization of Glycation-Sensitive Bovine Serum Albumin Peptides and Referenced in Comparison with Human Serum Albumin. Int J Clin Nutr Diet 3: 123. doi: https://doi.org/10.15344/2456-8171/2017/123

Page 3 of 5

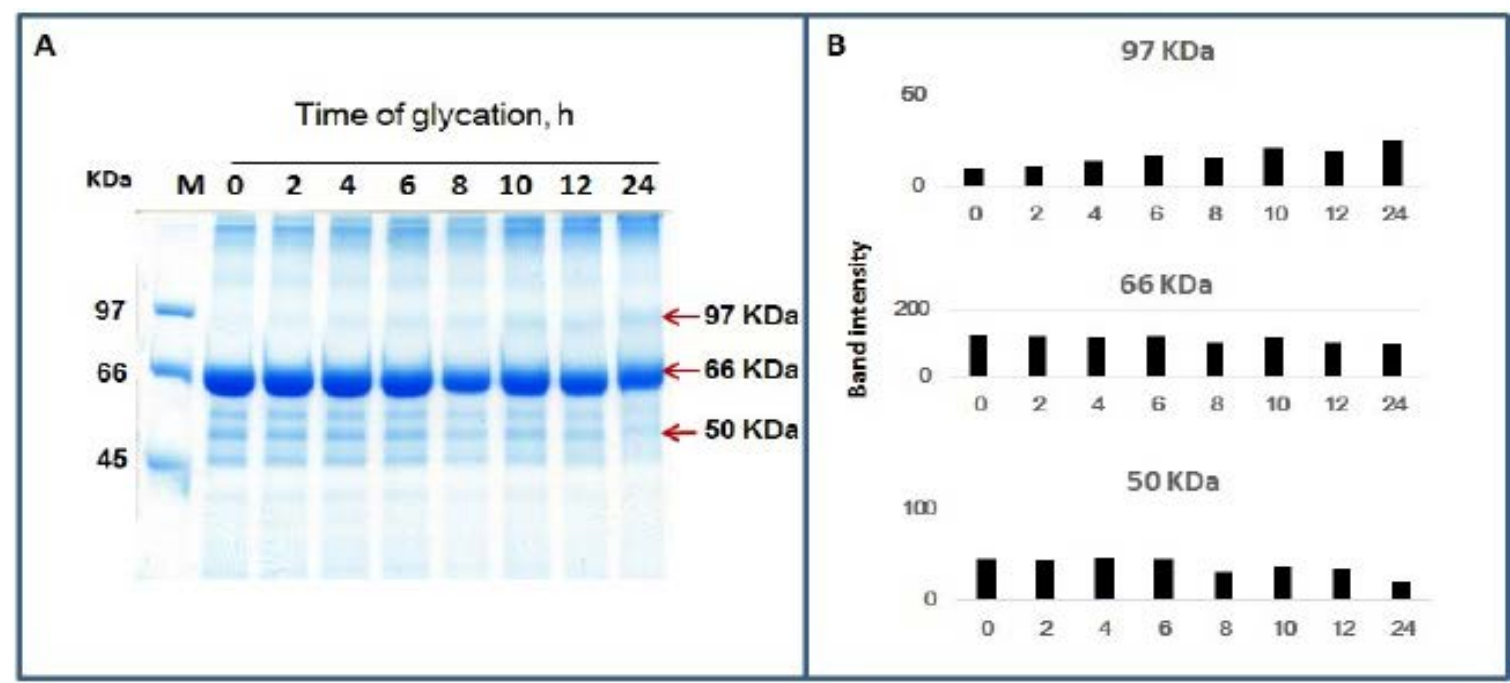

Figure 1: SDS-PAGE chromatogram (A) and intensities of the selected bands (B) of the reactant proteins of bovine serum albumin (BSA) reacted with fructose at $50^{\circ} \mathrm{C}$ for $0,2,4,6,8,10,12$ and $24 \mathrm{~h}$.

\section{Mascot Search Results: gi|1351907}

\section{A: $97 \mathrm{KDa}$}

\section{Protein sequence coverage: $\mathbf{4 9 \%}$}

Matched peptides shown in bold red.

1 MKAVTEISLL LLFSSAYSAG VERRDTHKSE IAHRYKDLGE EHFKOLVLIA 51 FSQYLQRCPF DEHUKLUVIEL, TEYAKTCVAD ESHAOCRKSL. HTLFGDELCK 101 VASLFETYGD MEDCCEKOEP ERNECFLSHK DDSFDLEKL. POPATLCDEF 151 KADEKKFKGK YLYELAR FHP YEYAPELLYY ANKYMGUFQE CCQNEDKGAC 201 LUPKTETMRE KVLASSAROR LRCASIOKPG ERALKAWSVA RLSOKFPKAE 251 FVEVTKLVTD LTKVHKECCH GDLLECADDR ADLAKYICDN QDTISSKLKE 301 OCDKDIISKS HCIAEVEKDA IDENLDDLTA DFAEDFEVCK MYCEAKDAFL 351 CSFLYEYSRR HPEYAVSVLL RLAKEYEATL EECCNYDDPH ACYSTVFDKL 401 KHIVDERONI. IKONCDOFEK LaRYGroNaL, IVRYTRKVPQ VSTPTLVEVS 451 RSLAKYGTAC CTKPESEFM CTEDYLSLIL RELCVLHEKT PUSEKVTKCC 501 TESLVNRAQC FSALTPOETY VPKAFDEKLF TFHADICTLP DTEKOIKKCI 551 ALVELTKHKP KATEEOLKTV MENFVAFVDK CCAADDKEAC PAVROPKLVV 601 sтотаLA

\section{B: $50 \mathrm{KDa}$}

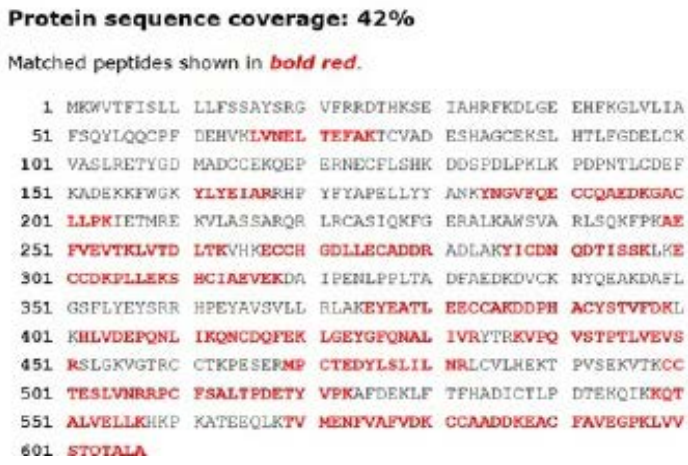

Matched peptides shown in bold red.

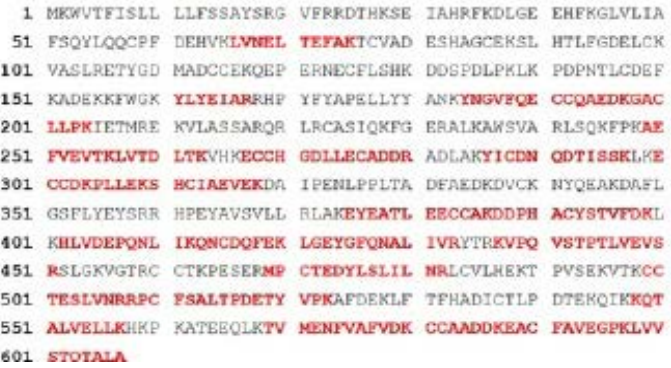

Figure 2. MASCOT search results with gi|1351907 of the SDS-PAGE bands with estimated molecular weights of $97 \mathrm{KDa}$ (A) and 50 $\mathrm{KDa}(\mathrm{B})$.

Appearnce and quantification of $97 \mathrm{KDa}$ band is normally regarded as measure of glycation $[1,4,14-16]$. As noticed, quantities of an original but minor band of BSA with MW $50 \mathrm{KDa}$ decreased gradually with time of glycation reaction (Figures $1 \mathrm{~A}$ and $1 \mathrm{~B}$ ). Based on band intensities of $66 \mathrm{KDa}$ shown in (Figure 1B), quantity of the major BSA comprising peptides also decreased gradually with time of glycation.

\section{Proteomic analysis of the 97 and $50 \mathrm{KDa}$ peptides}

After LC/MS/MS analyses, the trypsin-digested peptide sequences were subjected to MASCOT search with NCBInr Database for fingerprint matching with BSA gi|1351907 (Figure 2). For the 97 KDa peptide, the search results are: Score: 1634, Matches: 69(30), Sequences: 29(18), Protein sequence coverage $49 \%$. For the peptide with MW $50 \mathrm{KDa}$, the results are Score: 1392, Matches: 74(28), Sequences: 26(11), Protein sequence coverage 42\%. Accordingly, it is undoubted that 97 and $50 \mathrm{KDa}$ peptides are originating from BSA family. The BSA (RecName: Full=Serum albumin; AltName: Full=BSA; AltName: Allergen=Bos d 6; Flags: Precursor) comprises 607 amino acid residues with MW 69.2 KDa and 5.82 of isoelectric point (pI). When MASCOT search was applied to fingerprinting match with another NCBInr database of BSA gi|3674602, the coverage ratios for 97 and $50 \mathrm{KDa}$ were 51 and 44\%, respectively. The polypeptide of gi|367460260 (Chain A, Crystal Structure of Bovine Serum Albumin) contains 583 amino acid residues with MW $66.2 \mathrm{KDa}$ and 5.60 of pI. In comparison, both referenced polypeptides are only different in the first 24 aa. Basically, BSA gi|3674602 is a mature protein translated and transported after deletion of the first 24 amino acids observed in BSA gi|1351907. In this study, detailed searches are mainly based on BSA gi|1351907 (Figure 2).

In further comparison of the matching peptide segments between 97 and $50 \mathrm{KDa}$ polypeptides, many commonly overlapped segments are observed (marked with red color shown in Figure 2). In BSA domain 3 (aa 375-607) [1,4], the matched segments in 97 and 50 $\mathrm{KDa}$ peptides are identical except that K548 is only matched in 50 $\mathrm{KDa}$ peptide. However, there are 5 segments, belonging to BSA domains 1 and 2, only matched in peptide of $97 \mathrm{KDa}$. It is obvious that $50 \mathrm{KDa}$ is located in BSA domain 3. In literature, the lysine 
Citation: Lai LJ, Huang FL, Cheng PH, Chiou RYY (2017) SDS-PAGE Detection and Proteomic Characterization of Glycation-Sensitive Bovine Serum Albumin Peptides and Referenced in Comparison with Human Serum Albumin. Int J Clin Nutr Diet 3: 123. doi: https://doi.org/10.15344/2456-8171/2017/123

Page 4 of 5

residues including K256, K299, K420, K439 and K548 are regarded as active amino acid residues involved in glycation $[1,8,15-17]$. When BSA was subjected to reaction with glucose or galactose at $60^{\circ} \mathrm{C}$ for $120 \mathrm{~min}, \mathrm{~K} 256$ and $\mathrm{K} 420$ have been noticed as sensitive residues involved in glycation [16]. As generalized, those lysine residues except K548 (only detected in the peptide of $50 \mathrm{KDa}$ ) have been matched in both polypeptides. Thus, K548 might have been modified during glycation and, thus, not detected in $97 \mathrm{KDa}$.

Among the comparisons, it is of interest to point out the difference that the 10 aa-segment between E300 and K309 and K548 are only matched in the $50 \mathrm{KDa}$. This segment of ECCDKPLLEK (aa 300309) has been demonstrated as a glycation precursor by Ahmad et al. [15]. In that study, BSA has been subjected to reaction with glucose at $37^{\circ} \mathrm{C}$ for 5 weeks, the ECCDKPLLEK segment changed after 2 week reaction and disappeared after 5 weeks of reaction. Based on the finding that the SDS-PAGE detected $50 \mathrm{KDa}$ containing this glycation sensitive 10 aa-segment but not involved in formation of the glycated $97 \mathrm{KDa}$ peptide (a commonly detected indicator of glycated protein), decrease of $50 \mathrm{KDa}$ provides an alternative approach to monitor status of blood glycation.

As a further comparison addressed on the sequences adjacent to this 10 aa-segment between BSA and HSA (human serum albumin) (Appendix Figure 1) [8], KPLLEK in this segment along with the followed 8 aa-segment of SHCIAEVE are identical in both albumins. Therefore, the 14 aa-segment in HSA could be regarded as glycation sensitive target and used to develop a surveillance to monitor status of human blood. Similarly, in consideration of K548 as an active lysine residue in $50 \mathrm{KDa}$, the adjacent 11 aa-segment of Q545-L555
(QIKKQTALVEL) (Appendix Figure 1) is also identical between BSA and HSA and can be used as a target to develop a measure in monitoring human blood glycation as well.

\section{Queries in detection of AGEs-glycation precursor formation}

Segments of glyco-conjugates formed between AGEs and the glycation precursors have been searched by queries based on $\mathrm{m} / \mathrm{z}$ values obtained from LC ESI MS/MS (Table 1). As expected, K420, K557 and K580 are sensitive to react with fructose to form Schiff base/ AP as AGEs-precursor conjugates. K420 and K557 are also sensitive to form CML, pyrraline, imidazolon and AFGP as glyco-conjugates [15-20]. In addition, K214, R507, K523 and K526 have also been noticed being involved in formation of AGEs-precursor conjugates detected in the peptide of $97 \mathrm{KDa}$. As reported by Ahmad et al [15] to incubate BSA and glucose at $37^{\circ} \mathrm{C}$ for 5 weeks, conjugates of $\mathrm{H} 402 /$ $\mathrm{K} 412+$ Schiff base/AP was detected after 2 weeks of reaction and not detected after 5 weeks of glycation. This means that, after a prolonged period of glycation, the AGEs-precursor conjugates might degrade or be further modified.

When a query was made addressed on the 10 aa-segment (E300-K309, which was not matched in $97 \mathrm{KDa}$ ) as a precursor, the suspected AGEs-precursor conjugates was not detected (Table 1). This is further supporting that glycation of $50 \mathrm{KDa}$ was not involved in $97 \mathrm{KDa}$ formation. As queries were made addressed on K548, which was matched in the peptide of $50 \mathrm{KDa}$ (Figure 2), it is noteworthy to point the finding that that K548 is sensitive to react with Schiff base/ AP, CML, imidazolon and AFGP (Table 1) [15]. This is an evident clue to support why K548 was not matched in the glycated peptide

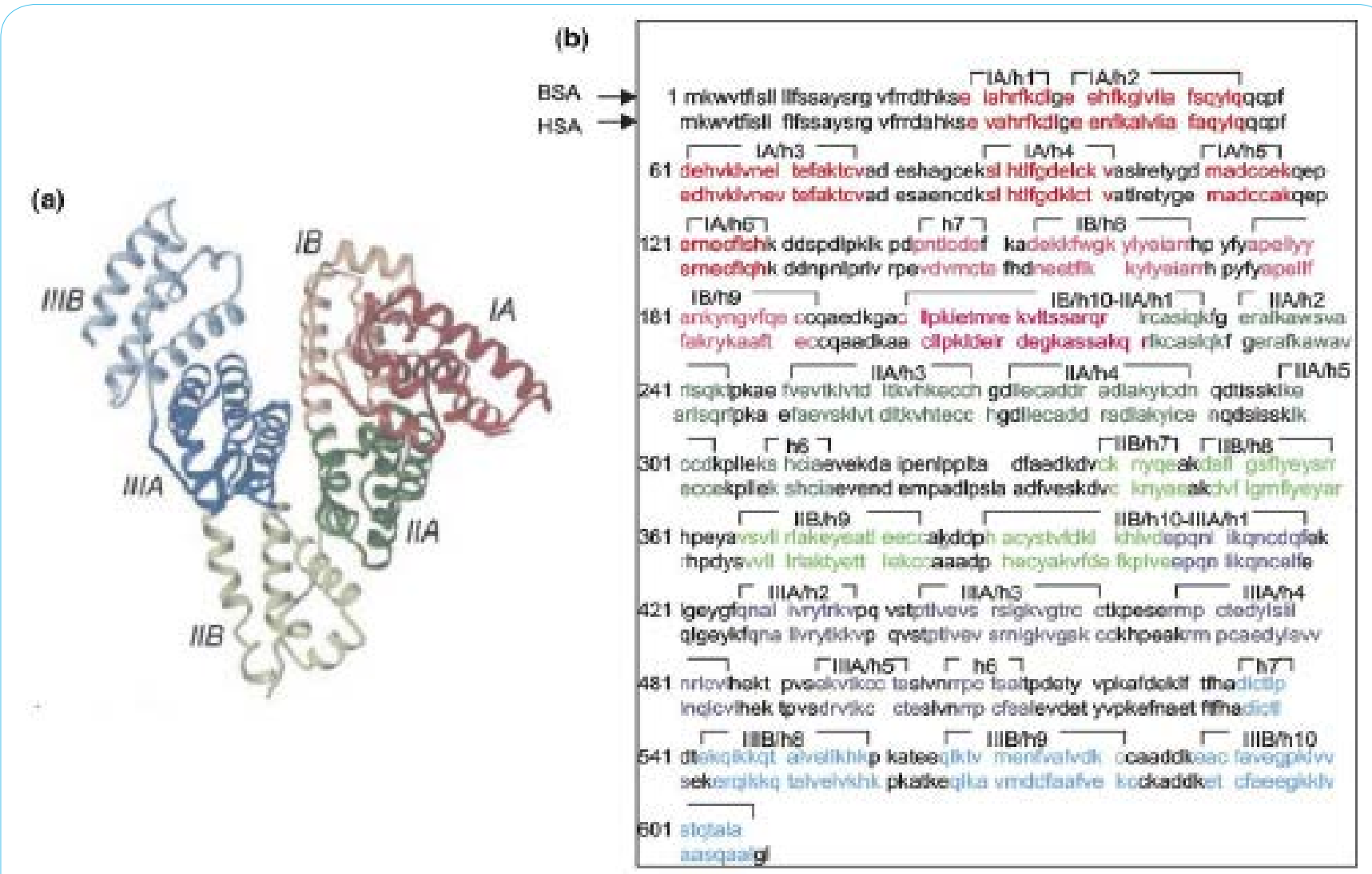

Appendix Figure 1: Domain structure and sequence homology of bovine and human serum albumin [8]. 
Citation: Lai LJ, Huang FL, Cheng PH, Chiou RYY (2017) SDS-PAGE Detection and Proteomic Characterization of Glycation-Sensitive Bovine Serum Albumin Peptides and Referenced in Comparison with Human Serum Albumin. Int J Clin Nutr Diet 3: 123. doi: https://doi.org/10.15344/2456-8171/2017/123

Page 5 of 5

of $97 \mathrm{KDa}$. Direct determination of AGEs and characterization of the AGEs-precursor conjugates to identify their possible pathophysiological roles for various diseases have been intensively investigated $[1,4,5,17,20-22]$ As mentioned above that the adjacent 11 aa-segment of Q545-L555 (QIKKQTALVEL) was similar to that if HSA (Appendix Figure 1), this segment deserves to be further used as a target to develop a measure in monitoring human blood glycation.

\section{Conclusion}

After subjection of BSA to an in vitro glycation with fructose at $50^{\circ} \mathrm{C}$ for $24 \mathrm{~h}$ and followed by SDS-PAGE analysis, an original 50 KDa peptide was disappearing with time along with appearance of the normally detected $97 \mathrm{KDa}$ glycated peptide. When the $50 \mathrm{KDa}$ and $97 \mathrm{KDa}$ bands were cut and subjected to LC MS/MS proteomic analysis and MASCOT fingerprint matches with sequences of BSA gi|1351907 and BSA gi|3674602 (NCBInr Database), the coverage ratios were 42 and $44 \%$ for $50 \mathrm{KDa}$ and 49 and $51 \%$ for $97 \mathrm{KDa}$, respectively. The segment of ECCDKPLLEK (aa 300-309 sharing a common segment of KPLLEK with that in HSA) was only detected in the $50 \mathrm{KDa}$ peptide. Apparently, $50 \mathrm{KDa}$ peptide is glycation sensitive but may not involve in formation of the detected glycated $97 \mathrm{KDa}$ peptide. In further search by manual queries addressed on $\mathrm{m} / \mathrm{z}$ values of the AGEs-precursor conjugates addressed on specified segments, K548 was of particular detected being active to form various AGEsprecursor conjugates. The adjacent 11 aa-segment of aa 545-555 (QIKKQTALVEL) is identical to that of HSA and deserves to use as a target to develop a measure in monitoring human blood glycation. Thus, segments of KPLLEK (aa 304-309) and QIKKQTALVEL (aa 545-555 containing K548 are of potency to use as a glycation-sensitive marker for development of rapid clinic assessment in surveillance of human health. In further, the segment of ECCDKPLLEK (aa 300309), has been demonstrated in the literature as a glycation precursor, was exclusively detected in the $50 \mathrm{KDa}$ peptide. This peptide is of potency to be used as a potential marker in development of a clinic alternative to measure status of human blood glycation.

\section{Competing Interests}

The authors declare that they have no competing interests.

\section{Funding}

Financial support from the Ministry of Science and Technology, Republic of China (NSC 97-2313-B415-008-MY3), is acknowledged.

\section{References}

1. Arasteh A, Farahi S, Habibi-Rezaei M, Moosavi-Movahedi AA (2014) Glycated albumin: an overview of the in vitro models of an in vivo potential disease marker. J Diabetes Metabolic Disorders 13: 49

2. Vlassara $H(2005)$ Advanced glycation in health and disease: role of the modern environment. Ann N Y Acad Sci 1043: 452-460.

3. Ulrich P, Cerami A (2001) Protein glycation, diabetes, and aging. Recent Progress Hormone Res 56: 1-22.

4. Lapolla A, Traldi P, Fedele D (2005) Importance of measuring products of non-enzymatic glycation of proteins. Clinical Biochem 38: 103-115.

5. Vlassara H, Bucala R, Striker L (1994) Pathogenic effects of advanced glycosylation: biochemical, biologic, and clinical implications for diabetes and aging. Lab Invest 70: 138-151.

6. Evans T (2002) Review article: albumin as a drug-biological effects of albumin unrelated to oncotic pressure. Aliment Pharmacol Ther 16: 6-11.
7. Gelamo E, Tabak M (2000) Spectroscopic studies on the interaction of bovine (BSA) and human (HSA) serum albumins with ionic surfactants. Spectrochim Acta A Mol Biomol Spectrosc 56: 2255-2271.

8. Huang BX, Kim HY, Dass C (2004) Probing three-dimensional structure of bovine serum albumin by chemical cross-linking and mass spectrometry. J Am Soc Mass Spectrom 15: 1237-1247.

9. Militello V, Vetri V, Leone M (2003) Conformational changes involved in thermal aggregation processes of bovine serum albumin. Biophys Chem 105: 133-141.

10. Arasteh A, Habibi M, Habibi AE, Moosavi-Movahedi AA (2011) Bovine serum albumin aggregation: An optimizing approach. Clin Biochem 44: S136-S137.

11. Brewer SH, Glomm WR, Johnson MC, Magne K, Franzen S, et al. (2005) Probing BSA binding to citrate-coated gold nanoparticles and surfaces. Langmuir 21: 9303-9307.

12. Taboada P, Gutiérrez-Pichel M, Mosquera V (2004) Effects of the molecular structure of two amphiphilic antidepressant drugs on the formation of complexes with human serum albumin. Biomacromolecules 5: 1116-1123.

13. Dockal M, Carter DC, Rüker F (2000) Conformational transitions of the three recombinant domains of human serum albumin depending on $\mathrm{pH}$. J Biol Chem 275: 3042-3050.

14. Wang SH, Chang JC, Pokkaew R, Lee JF, Chiou RYY (2011) Modified fast procedure for the detection and screening of antiglycative phytochemicals. J Agric Food Chem 59: 6906-6912.

15. Ahmad W, Li L, Deng Y (2008) Identification of AGE-precursors and AGE formation in glycation-induced BSA peptides. BMB Reports 41: 516-522.

16. Ledesma-Osuna Al, Ramos-Clamont G, Vázquez-Moreno L (2008) Characterization of bovine serum albumin glycated with glucose, galactose and lactose. Acta Biochim Pol 55: 491-497.

17. Hinton D, Ames J (2006) Site specificity of glycation and carboxymethylation of bovine serum albumin by fructose. Amino Acids 30: 425-434.

18. Kikuchi S, Shinpo K, Ogata A, Tsuji S, Takeuchi M, et al. (2002) Detection of $\mathrm{N}$ epsilon-(carboxymethyl)lysine (CML) and non-CML advanced glycation end-products in the anterior horn of amyotrophic lateral sclerosis spinal cord. Amyotroph Lateral Scler Other Motor Neuron Disord 3: 63-68.

19. Fu MX, Requena JR, Jenkins AJ, Lyons TJ, Baynes JW, et al. (1996) The advanced glycation end product, $\mathrm{N}$-(carboxymethyl) lysine, is a product of both lipid peroxidation and glycoxidation reactions. J Biol Chem 271: $9982-$ 9986.

20. Dyer D, Blackledge J, Thorpe S, Baynes J (1991) Formation of pentosidine during nonenzymatic browning of proteins by glucose. Identification of glucose and other carbohydrates as possible precursors of pentosidine in vivo. J Biol Chem 266: 11654-11660.

21. Nakayama M, Kawaguchi $\mathrm{Y}$, Yamada K, Hasegawa T, Takazoe K, et al (1997) Immunohistochemical detection of advanced glycosylation endproducts in the peritoneum and its possible pathophysiological role in CAPD. Kidney Int 51: 182-186.

22. Niwa T, Katsuzaki T, Ishizaki Y, Hayase F, Miyazaki T, et al. (1997) Imidazolone, a novel advanced glycation end product, is present at high levels in kidneys of rats with streptozotocin-induced diabetes. FEBS letters 407: 297-302. 